\title{
Development of drilling well irrigation to meet water needs in the rainfall of Sambirejo village, Kabupaten Langkat
}

\author{
R.A. Sembiring ${ }^{* 1}$, C. Asda $^{1}$, R.A. Dewi ${ }^{1}$, A. Ananta ${ }^{1}$, M.A. Pulungan ${ }^{1}$ \\ ${ }^{1}$ Department of Civil Engineering, Faculty of Engineering, Universitas Sumatera Utara, Medan, \\ Indonesia \\ *Email: robisembiring@usu.ac.id
}

\begin{abstract}
One very important element in agriculture is water. The availability of water must be guaranteed so that plants can grow throughout the year. The lack of water availability means that crops cannot be produced throughout the year, causing farmers to become inadequate. Engineering irrigation is one of the systems that can regulate water availability throughout the year, but not all regions in Indonesia have such irrigation. Sambirejo Village is one of the villages in Langkat Regency which still utilizes a rainfed irrigation system. The main problem from Sambirejo Village, especially the Karya Tani Farmer Group, which is a service partner, is the unavailability of water to irrigate rice fields during the dry season. This unavailability of water causes a reduction in the productivity of farmers who are supposed to harvest three times to only twice a year. Through community service activities carried out the construction of borehole irrigation in Sembirejo Village. This method utilizes ground water as a source of water supply during the dry season. Drilled well irrigation can be enjoyed directly by farmers in the vicinity of the service area, and in the dry season the water needs for plants are available.
\end{abstract}

Keyword: Farmers, Drought, Irrigation, Groundwater

\begin{abstract}
Abstrak
Salah satu unsur yang sangat penting pada pertanian adalah air. Ketersediaan air harus terjamin agar tanaman dapat tumbuh sepanjang tahun. Ketersediaan air yang kurang menagkibatkan tanamana tidak dapat diproduksi sepanjang tahun sehingga menyebabkan penghasilan petani menjadi tidak maksimal. Irigasi teknik merupakan salah satu sistem yang dapat mengatur ketersediaan air sepanjang tahun, namun tidak semua daerah di Indonesia memiliki irigasi tersebut. Desa Sambirejo merupakan salah satu desa di Kabupaten langkat yang masih memanfaatkan sistem irigasi tadah hujan. Masalah utama dari dari Desa Sambirejo khususnya Kelompok Tani Karya Tani yang merupakan mitra pengabdian adalah tidak tersedianya air untuk mengairi sawah pada saat musim kemarau. Tidak tersedianya air ini menyebabkan pengurangan produktivitas petani yang seharusnya panen tiga kali menjadi hanya dua kali dalam setahun. Melalui kegiatan pengabdian kepada masyarakat dilakukan pembangunan irigasi sumur bor di Desa Sembirejo. Metode ini memanfaatkan air tanah sebagai sumber penyedia air pada saat musim kemarau. Irigasi sumur bor yang dibuat dapat dinikmati secara langsung oleh petani di sekitar lokasi pengabdian, dan pada musim kemarau kebutuhan air untuk tanaman sudah tersedia.
\end{abstract}

Kata Kunci : Petani,Kemarau, Irigasi, Air Tanah

\section{PENDAhuluan}

Khalayak sasaran pada Program Pengabdian Kepada Masyarakat merupakan masyarakat umum Desa Sambirejo yang mayoritas penduduknya bermata pencaharian sebagai petani. Masyarakat setempat hidup dan tinggal dengan memanfaatkan lahan pertanian sebagai sumber mata pencaharian. Selain sebagai petani, beberapa masyarakat juga berprofesi sebagai pegawai negeri sipil. Pertanian di Desa Sambirejo merupakan pertanian dengan sistem tadah hujan. Petani memanfaatkan air hujan sebagai sumber utama irigasi. Pada musim kemarau, kebutuhan air untuk pertanian di Desa Sembirajo tidak terpenuhi, sehingga lahan pertanian mengalami kekeringan. Pertanian dengan sistem sawah yang hanya mengandalakan tadah hujan 
mengakibatkan petani tidak dapat berproduksi pada musim kemarau. Berdasarkan kondisi tersebut, maka perlu dipikirkan alternatif lain untuk memenuhi kebutuhan air tanaman dari sumber air yang lain. Salah satu alternatif sumber air yang dapat dikembangkan untuk kebutuhan pertanian adalah pemanfaatan air tanah.

Pemanfaatan air tanah untuk pertanian dapat dilakukan dengan membuat irigasi sumur bor. Berdasarkan pemanfaatannnya, irigasi air tanah dapat dibedakan menjadi irigasi sumur bor dan irigasi air tanah dalam. Hal tersebut sangat berkaitan dengan kebutuhan infrastruktur dan pemanfaatan air tanah. Daerah yang memiliki potensi untuk dibuat sumur bor, akan lebih mudah untuk dimanfaaktan karena kebutuhan infrastrukturnya lebih sederhana. Hal tersebut akan memudahkan petani setempat untuk mengembangkannya secara mandiri atau jika masih membutukan dukungan masih pada tingkat terbatas.. Sumber air tanah yang dimanfaatkan pada sumur bor umumnya berada pada lapisan - lapisan tanah yang tidak begitu dalam, sehingga masih bisa diakses menggunakan pompa.

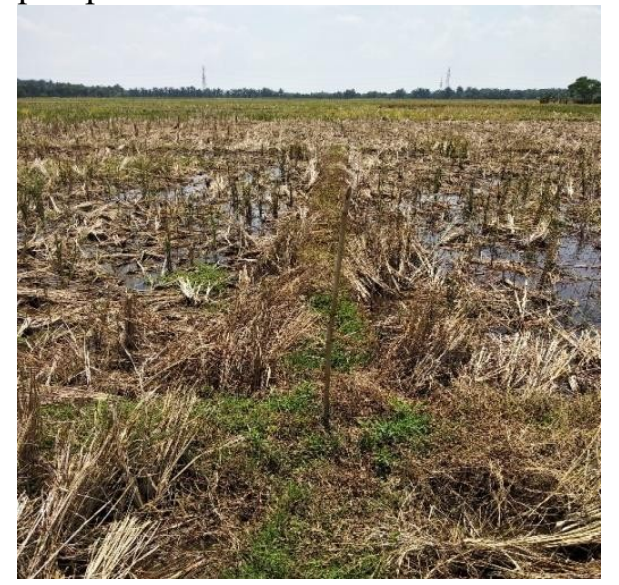

Gambar 1.1. Kondisi Lahan pertanian di desa Sambirejo

\section{METODE PELAKSANAAN}

Pelaksanaan Program Pengabdian kepada Masyarakat Universitas Sumatra Utara untuk mono tahun dilakukan di Desa Sambirejo, Kecamatan Binjai.Denah lokasi kegiatan pengabdian dapat dilihat pada gambar 2.1.

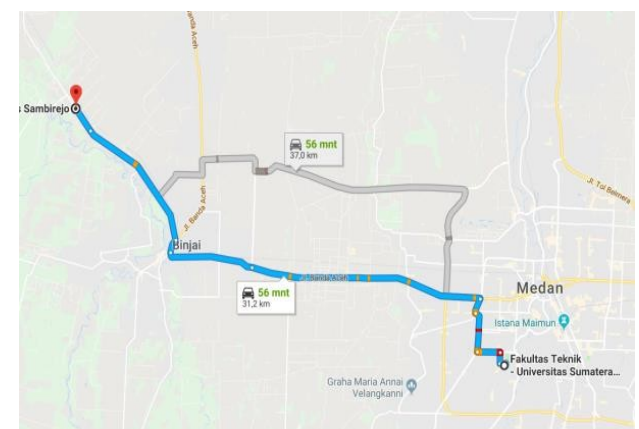

Gambar 2.1. Denah Lokasi kegiatan Program Pengabdian kepada Masyarakat

Program Pengabdian Kepada Masyarakat yang dilakukan berupa pembangunan irirgasi sumur bor. Pelaksanaan program pengabdian ini dilakukan oleh tukang, dan masyarakat sekitar, serta beberapa mahasiswa dari Universitas Sumatra Utara. Adapun tahapan pelaksanaannya adalah sebagai berikut.

1) Studi literatur

Bertujuan untuk menentukan metode atau cara kerja yang efisien dan efektif sesuai dengan permasalahan dilokasi mitra Program Pengabdian kepada Masyarakat. 
2) Tahap analisis

Tahap analisis dibutuhkan untuk merencanakan dimensi sumur resapan dan talang air yang dibutuhkan.

3) Persiapan bahan dan alat yang dibutuhkan

Bertujuan untuk mempersiapkan peralatan dan material yang diperlukan saat pembuatan sumur resapan. Alat dan materialnya disesuaikan dengan lokasi pengabdian.

4) Pengeboran Sumur

Air tanah dapat dimanfaatkan untuk irigasi dengan cara membuat sumur sebagai tempat pengambilan. Sumur yang digunkana dapat berupa sumur gali dan sumur bor. Dibuat sesuai dengan keddalaman air tanah.

5) Pemasangan Pompa Air

Pompa air digunakan untuk mengambil air dari sumur ke permukaan tanah. Jenis pompa yang digunakan untuk sumur bor biasanya adalah pompa yang berjenis sentrifugal. Pompa yang digunakan bersifat dapat dipindah- pindahkan. Dimana satu pompa dapat digunakan untuk memfasilitasi beberapa sumur.

6) Pembangunan Peralata Pelengkap

Bangunan/peralatan pelengkap berupa dudukan pompa yang terbuat dari beton, pipa, selang hisap, dan selang buang.

\section{HASIL DAN PEMBAHASAN}

Pelaksanaan Kegiatan pengabdian kepada masyarakat berupa pembangunan irigasi sumur bor ini dimulai pada bulan april sampai bulan september.. Semua tahapan kegiatan dilaksanakan langsung di tempat lokasi pengabdian. Sebelum pelaksanaan kegiatan dilakukan rapat koordinasi dengan masyarakat setempat membahas pelaksanaan kegiatan pengabdian yaitu pembuatan irigasi sumur bor.

Pada tahap awal dilakukan studi literatur dan analisa untuk menentukan ukuran dimensi sumur resapan dan talang air, kegiatan ini dilakukan oleh tim pengabdian dan dibantu oleh mahasiswa Universitas Sumatera Utara. Gambar dan ukuran dimensi dari sumur bor yang dibuat dapat dilihat pada gambar 3.1.

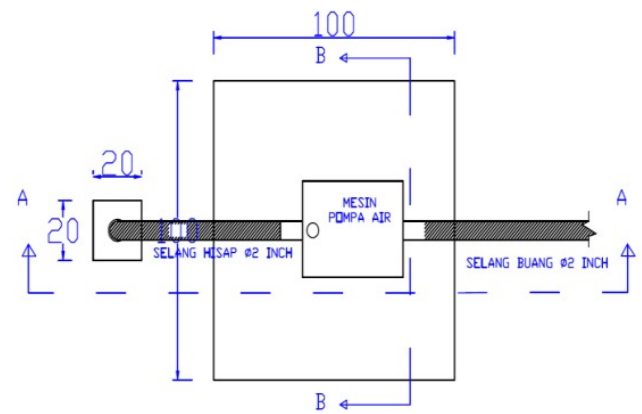

Gambar 3.1. Tampak atas bangunan irigasi sumur bor 


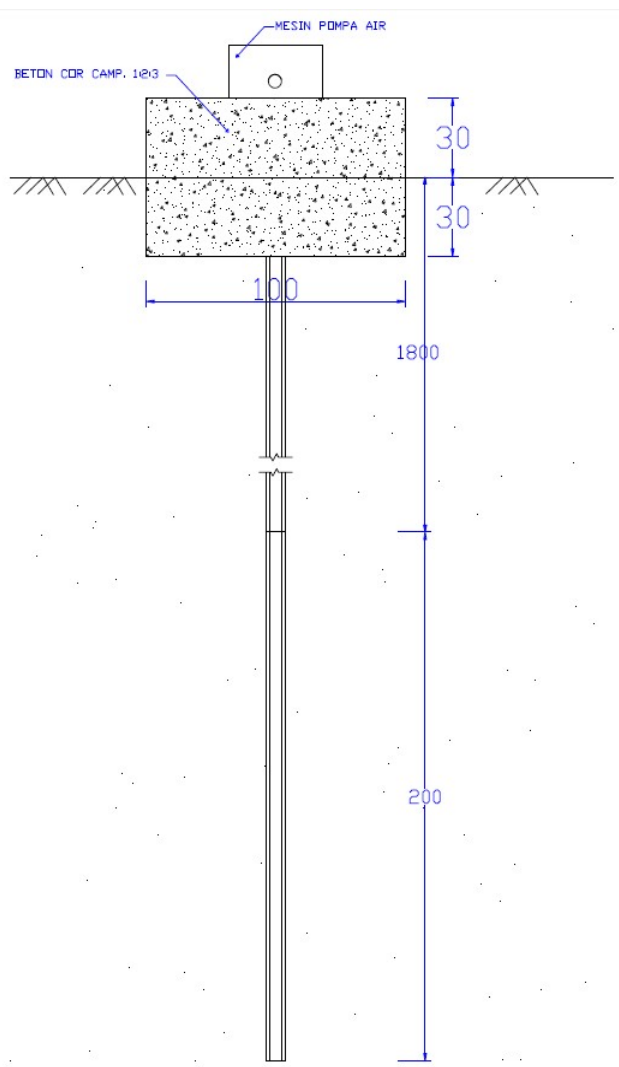

(a)

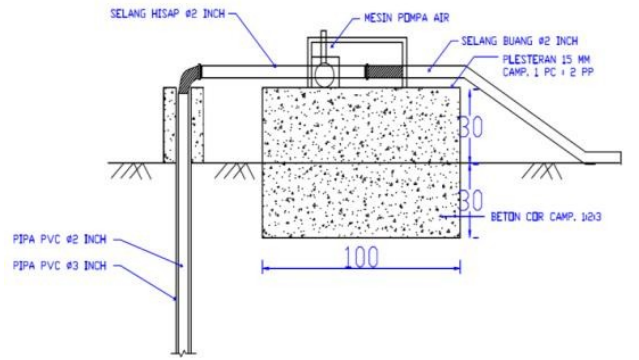

(b)

Gambar 3.2. (a) Potogan A-A bagunan irigasi sumur bor, (b) Potogan B-B bagunan irigasi sumur bor.

Tahapan selanjutnya adalah dilakukan pengeboran sumur, pemasangan pompa sumur, dan membangun peralatan pelengkap. Tahapan ini dilakukan oleh tukang dan diawasi oleh tim pengabdian, mahasiswa Universitas Sumatra Utara dan masyarakat Setempat. Dokumentasi pelakasanaan penggalian sumur bor dan dudukan mesin pompa air dapat dilihat pada Gambar 3.3 dan Gambar 3.4.

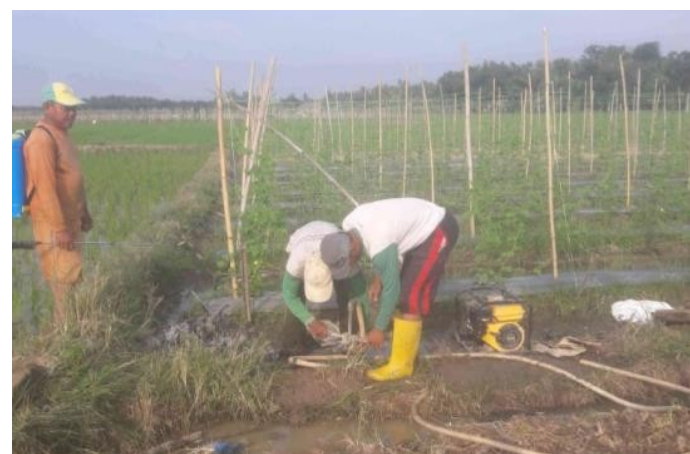

Gambar 3.3. Proses penggalian sumur Bor 


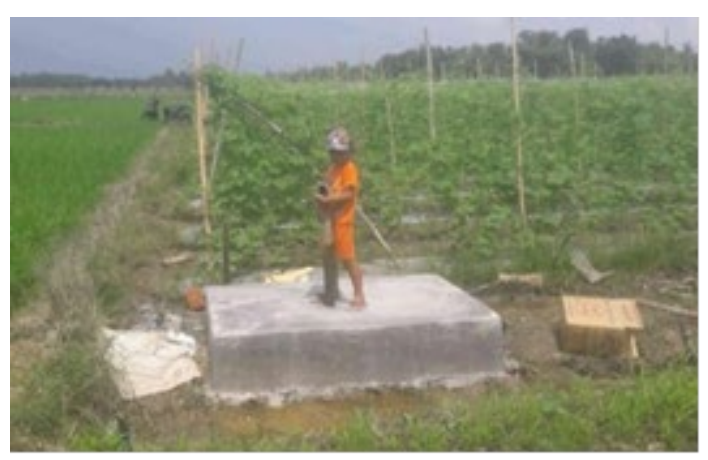

Gambar 3.4. Dudukan Mesin Pompa air

Kerjasama antara tim pengabdian dengan masyarakat sekitar sangat membantu dalam penyelesaian pembuatan sumur resapan dengan tepat waktu sehingga dengan segera bisa berfungsi menampung limpasan air hujan. Dengan adanya irigasi sumur bor ini, Lahan pertanian dapat dialiri air walaupun pada saat musim kemarau.

Sebagai tanda pelaksanaan kegiatan pelaksanaan pengabdian lepada masyarakat, dilakukan pemasangan papan informasi lokasi pengabdian seperti pada Gambar 3.5.

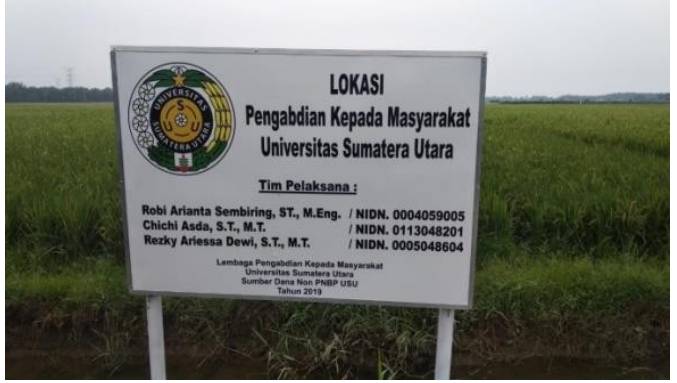

Gambar 3.5. Pemasangan Papan Informasi Lokasi Pengabdian

\section{KESIMPULAN DAN SARAN}

Pembangunan irigasi sumur bor dari program pengabdian kepada masyarat di desa Sambirejo kabupaten langkat sudah terealisasi. Pembangunan irigasi sumurr bor sudah dapat dinikmati secara langsung oleh para petani di sekitar lokasi pengabdian. Kebutuhan air di lahan pertanian desa Sambirejo sudah dapat terpenuhi walau musim kemarau.

Saran yang diberikan untuk kegiatan ini antara lain:

1) Diharapkan, masyarakat desa sambirejo menjaga dan merawat irigasi sumur bor yang dibangun agar dapat terus membantu petani mengairi lahan pertanian sekitar lokasi pengabdian terutama pada musim kemarau

2) Tim pengabdian juga berharap kegiatan pengabdian berfungsi dalam membantu memenuhi kebutuhan sarana prasarana di lokasi pengabdian

\section{UCAPAN TERIMAKASIH}

Artikel ini merupakan salah satu hasil dari Program Pengabdian kepada Masyarakat yang Dibiayai oleh dana NON PNBP Universitas Sumatera Utara Sesuai dengan Surat Perjanjian Penugasan Pelaksanaan Pengabdian kepada Masyarakat Program Mono Tahun Dosen Muda Tahun Anggaran 2019. Oleh karena itu, diucapkan terima kasih kepada Rektor Universitas Sumatera Utara atas dukungan dana dan fasilitas yang diberikan. Terima kasih juga kepada Mitra pada kegiatan pengabdian ini. 


\section{DAFTAR PUSTAKA}

Anonim, 2004, Pedoman Teknis Konstruksi Jaringan Irigasi Air Tanah Sistim Perpipaan, Dit. Irigasi, Ditjen Sumber Daya Air: Departemen Pekerjaan Umum.

Anonim, 1994, Petunjuk Teknis Pengembangan Pompa Sumur Bor, Proyek Pengembangan Sumberdaya Sarana dan Prasarana Tanaman Pangan dan Hortikultura, Direktorat Bina Rehabilitasi dan Pengembangan Lahan: Jakarta.

Anonim, 2002, Pedoman Teknis Pengembangan Irigasi Pompa, Direktorat Pemanfaatan Air Irigasi, Direktorat Jenderal Bina Sarana Pertanian, Departemen Pertanian: Jakarta.

Anonim, 2004, Penyusunan Database Sarana Air Tanah Untuk Irigasi Pertanian, Laporan Akhir PT. Gita Rencana Multiplan, Direktorat Pemanfaatan Air Irigasi, Direktorat Jenderal Bina Sarana Pertanian, Departemen Pertanian: Jakarta.

Sosrodarsono, Suyono dan Takeda, Kensaku, 2003, Hidrologi Untuk Pengairan, PT. Pradnya Paramita: Jakarta. 